\title{
Üniversite Öğrencileri için Bilgisayar Tabanlı Sürdürülebilir Dikkat Testi Norm Çalışması*
}

\section{A Norm Study of Computerized Sustained Attention Test among University Students ${ }^{\dagger}$}

\author{
Hale Ilgaz, Ankara Üniversitesi, hilgaz@ankara.edu.tr ORCID: 0000-0001-7011-5354 \\ Mehmet Kokoç, Trabzon Üniversitesi, kokoc@trabzon.edu.tr ORCID: 0000-0002-1347-8033 \\ Arif Akçay, Kastamonu Üniversitesi, aakcay@kastamonu.edu.tr ORCID: 0000-0001-9103-9469 \\ Arif Altun, Hacettepe Üniversitesi, altunar@hacettepe.edu.tr ORCID: 0000-0003-4060-6157
}

\begin{abstract}
Öz. Sürdürülebilir dikkat, dikkatin temel bir bileşeni olmakla birlikte uzun zaman aralıkları boyunca sıklıkla ve beklenmedik bir şekilde gelişen uyaranlara karşı hazır olma hali olarak tanımlanmaktadır. Bireylerin dijital ekranlarla uzun süre vakit geçirdikleri e-öğrenme ortamlarında da sürdürülebilir dikkatin araştırılması önemlidir. Bu çalışmada bilgisayar tabanlı bir sürdürülebilir dikkat testinin norm çalışmasının yapılması amaçlanmıştır. Araştırmada iki farklı üniversiteden 201 katılımcı yer almaktadır. Çoklu nesne takibi paradigmasına göre geliştirilmiş olan testten elde edilen verilere göre erkek katılımcıların sürdürülebilir dikkat performansları kadın katılımcılara göre daha yüksek çıkmıştır. Yaş değişkeni açısından ise gruplar arasında anlamlı bir farklılık bulunamamıştır. Bu sürdürülebilir dikkat testi ile e-öğrenme ortamlarının tasarımlarında bireysel farklılıkları dikkate alan uygulamalar geliştirilmesi sürecinde ön değerlendirmeler yapılıp, farklı tasarım önerileri geliştirilebilir.
\end{abstract}

Anahtar Sözcükler: Sürdürülebilir dikkat, e-öğrenme, tasarım, bireysel farklıllklar

\begin{abstract}
Sustained attention can be defined as being a basic component of attention and being ready for stimuli that develop frequently and unexpectedly over long periods of time. It is important to investigate sustained attention in e-learning environments where individuals spend a long time with digital screens. The aim of this study was to conduct a normative study of a computer-based sustained attention test. In the research, there are 201 participants from two different universities. According to the data obtained from the test developed according to the multi-object tracking paradigm, the sustained attention performance of male participants was higher than that of female participants. In addition to this finding, no significant difference was found between the groups in terms of age variables. With this sustained attention test, pre-evaluations can be made in the process of developing applications that take into account individual differences in the design of e-learning environments and allow different design proposals to be developed.
\end{abstract}

Keywords: Sustained attention, e-learning, design, individual differences

\footnotetext{
* Bu çalışma, 117K663 numaralı TÜBİTAK projesi kapsamında gerçekleștirilmiştir.

† This study was funded by the Scientific and Technological Research Council of Turkey (Project No: 117K663).
} 


\section{SUMMARY}

\section{Introduction}

Attention is a structure that enables individuals to survive, learn and develop from the moment they were born. Learning environments such as the outside world also contain a large number of stimuli. Attention has a very important role in ignoring the irrelevant stimuli and taking the relevant stimuli. Attention is a behavioral and cognitive process, which is a perception of a specific aspect of information or stimulus. Developed theories of attention reveal the existence of different types of attention. Selective, divided, and sustained attention is among these types of attention. Sustained attention is defined as being a basic component of attention, but also as readiness for stimuli that develop frequently and unexpectedly over long periods of time. While sustained attention is a more fundamental function of attention, selective attention has an important role in determining the effectiveness of further aspects of attention, such as divided attention or general cognitive capacity (Sarter, Givens \& Bruno, 2001). There is no effective recognition, learning, and memory in a learning process where sustained attention is not included (Broadbent, 1958). Ilgaz, Altun, and Așkar (2014) found that sustained attention has no significant effect on implicit memory performance in their study of the effects of sustained attention and contextual clue on implicit memory performance in e-learning environments. In this study, the Multiple Object Tracking Test developed by Pylyshyn and Haladjian (2006) was used according to multiple object-tracking paradigm. The aim of this study was to conduct a normative study of a computer-based sustained attention test in Turkey. In the context of this aim, the implementation of the test, which was adapted to the Turkish language by Ilgaz, Altun, and Aşkar (2014) and contains three levels, was reported and the distributions in terms of gender and age variables were reported.

\section{Method}

The research was carried out using descriptive research methods. The data obtained in this context were analyzed and reported. Sustained attention test consists of three stages: easy, moderate and difficult. Sustained attention test consists of three stages: easy, moderate and difficult. In practice, eight balls are displayed. A certain number of balls are flashing from each of these balls to match each level, showing the balls to be followed by the participant. After this level, all the balls are moved in a random manner on the screen for 10 seconds. Participants are expected to follow the blinking targets first and to identify targets when all balls are stopped. At the easy level, one of the total eight objects is the target, two are the target at the moderate level, and four are targeted at the difficult level and each level repeats 10 times. At least "0 "and maximum " 10 " points are taken from each level of the test. The expert project team member carried out tests individually. A total of 201 university students (88 females and 113 males) with no advanced visual impairment (normal and corrected vision) participated in the study. Descriptive analysis, Mann Whitney U and Kruskal Wallis $\mathrm{H}$ test were used to analyze the data.

\section{Results}

The findings obtained from the analysis of the data show that when the scores obtained from the sustained attention test are examined, the average score decreases as the difficulty level of the test increases. The Mann Whitney U test was applied to determine the relationship between the scores obtained from the general, the points obtained from the sustained attention test and the gender variable. Participants' scores on the sustained attention test showed a significant difference in the moderate and difficult level according to the gender variable. Sustained attention performance of male participants was higher than female participants. The Kruskal Wallis $\mathrm{H}$ test was applied to determine the relationship between the scores obtained from the general, the points obtained from the general and the age variable of the participants. 
Looking at the results obtained from this analysis, there is no relationship between the participants' age variable and sustained attention performance.

\section{Discussion and Conclusion}

Demographic variables such as age, gender, socio-economic status are important variables for many research subjects as well as for studies dealing with cognitive processes. The data obtained from this study show that as test levels progressed, male participants get higher scores than female participants. In the literature, there was no significant difference between men and women in one of the studies on sustained attention in terms of gender variable (Chan, 2001), while another study found that men performed better than women (Riley et al., 2016). In addition, the level of attention of men is higher (Blatter et al., 2006) and suppressive elements in women (Yuan, He, Qinglin \& Chen, 2008). No significant relationship was found between participants' age-related sustained attention performance. Dye and Hauser (2014) found significant differences between the age groups of the children in both groups in their study of the levels of sustained attention of deaf and hearing children. Developmentally sustained attention performance takes place as a research topic in children (Betts, McKay, Maruff \& Anderson, 2006; Lin, Hsiao \& Chen, 1999). There are research results about the development of sustained attention especially in childhood between 5-6 and 11-12 years of age. (Klenberg, Korkman, \& Lahti-Nuuttila, 2001; Manly et al., 2001; Rebok et al., 1997). The fact that the participants in this study consisted of adult individuals and that no significant difference in performance according to age groups showed any significant difference may be seen due to the completion of the attention development process.

\section{GíRiş}

Dış dünyada çok fazla sayıda uyaran bulunmaktadır. Bu kadar fazla uyaranın olduğu ortamlarda duyu sistemi de diğer iletişim araçları gibi kapasitesi ölçüsündeki bilgiyi işleyebildiğinde etkili bir şekilde çalışır, bu kapasitenin üzerinde bilgi yüklendiği zaman ise başarısız olmaktadır (Solso, Maclin ve Maclin, 2009). Öğrenme içsel psikolojik bir süreç olup duyusal farkındalık, dikkat, tanıma, dönüştürme, bellek yapılar ile bilginin alınması ve uygulanmasını içermektedir. Bilgi işleme sürecinin psikolojik boyutunda bireyin bilgiyi alması dikkatle başlamaktadır (Atkinson ve Shiffrin, 1968). Dikkat, sınırlı bilişsel kapasitenin kaynaklarının paylaştırılması olarak tanımlanabilir (James, 1980).

Dikkat davranışsal ve bilişsel bir süreç olup bilginin ya da uyaranın belirli bir yönünün algılanmasıyla oluşmaktadır. Bir tür uyarılma hali olarak da görülebilen dikkat, bir düşünce dizisine ya da nesnelere yönelik zihnin net ve canlı bir pozisyon almasıdır. Bilincin odaklanması, konsantrasyon dikkatin temelindedir. Dikkat sürecini inceleyen kuramlardan ilki Broadbent (1958)'in ortaya koymuş olduğu Filtreleme Kuramı'dır. Filtreleme kurama göre bireyler aynı anda sadece bir uyarana dikkat edebilmektedirler ve ilk olarak uyaranın fiziksel özellikleri kodlanır. Sonrasında uyarana ait soyut ve anlamsal özelikler kodlanmaktadır. Bu kurama Treisman (1960) tarafından eklemeler yapılmış ve Özellik Tamamlama Kuramı geliştirilmiştir. Filtreleme Kuramı'ndan farklı olarak kodlanamayan fiziksel özelliklerin korunmasıdır. Bu özellikler algı kanallarından geçerek az miktar da olsa işleme alındıklarını ortaya koymaktadır. Bu seçim sürecinde de bireylerin geçmiş deneyimleri ve yaşamı etkili olmaktadır. Dikkatle ilgili geliştirilen bir diğer kuram ise Geç Seçim Kuramı'dır ve Deutsch ve Deutsch (1963) tarafından geliștirilmiștir. Bu kurama göre uyaranlar yalnızca fiziksel ve anlamsal özelliklerine göre analiz edildikten sonra filtreden geçmektedir. Kapasite Kuramı ise Kahneman (1973) tarafından ortaya konmuştur. Kahneman'a göre dikkat, sınırsız bir kaynak olmamakla birlikte paylaştırılan bir kaynaktır. Bireylerin bilgi işleme kapasitelerinin kısıtlılıkları çerçevesinde var olan kaynakların işlem önceliğine göre konumlanmasını içermektedir. 
Dikkatle ilgili geliştirilmiş olan kuramlar farklı dikkat türlerinin varlığını ortaya koymaktadır. Seçici (selective) dikkat, bölünmüş (divided) dikkat ve sürdürülebilir (sustained) dikkat bu dikkat türleri arasında yer almaktadır. Seçici dikkat; bireyin herhangi bir dikkat dağıtıcı uyarana odaklanmadan belli bir uyarana yönelmesi olarak tanımlanmaktadır. Bilginin seçimi aşamasında bireyler bazı uyaranlara diğerlerinden daha kolay dikkatlerini yönlendirmektedirler. Bu süreçteki işleyen mekanizmaya seçici dikkat adı verilmektedir. Bölünmüş dikkat; bireyin aynı anda birden fazla görevi yerine getirirken yürütülen bir mekanizmadır ve çoklu görev olarak da anılır. Sürdürülebilir dikkat ise dikkatin belli bir noktaya uzun süre odaklanmasıyla ve konsantrasyonla sürekli bir şekilde tek bir göreve dikkatin yönlendirildiği bir dikkat türü olarak tanımlanmaktadır (Roda, 2011; Schweizer, 2010).

Sürdürülebilir dikkat, dikkatin temel bir bileșeni olmakla birlikte uzun zaman aralıkları boyunca sıklıkla ve beklenmedik bir şekilde gelişen uyaranlara karşı hazır olma hali olarak da tanımlanmaktadır. Sürdürülebilir dikkat, dikkatin daha temel bir fonksiyonu olmasına rağmen seçici dikkat, bölünmüş dikkat ya da genel bilişsel kapasite gibi dikkatin daha ileri yönlerinin etkililiğini belirlemesinden dolayı önemli bir role sahiptir (Sarter, Givens ve Bruno, 2001).

Sürdürülebilir dikkat çalışmaları Mackworth'ün (1948) İkinci Dünya Savaşı zamanında radar operatörlerinin belli bir zaman içinde hedefleri tespit etmedeki becerilerinin düşmesinin belirlenmesiyle başlamış bulunmaktadır. Performanslarındaki bu düşüş genellikle sürdürülebilir dikkat çalışmalarında etkisini göstermektedir. Özellikle hava trafik kontrolörlüğü ya da radar operatörlüğü gibi dikkatin uzun sürelerce kesintisiz olarak yürütüldügü görevlerde sürdürülebilir dikkatin önemi çok büyüktür (Helton, Kern ve Walker, 2009). Sürdürülebilir dikkat, dikkat dağıtıcı uyaranların reddedilmesi ve ilgisiz etkinliklere dikkatin geçişinin engellenmesi ile doğrudan ilgili olmasından dolayı hem günlük yaşam hem de öğrenme süreçleri açısından araştırılması önemli yapılardan birisidir.

Sürdürülebilir dikkatin yer almadığı bir öğrenme sürecinde etkili tanıma, öğrenme ve hafızaya alma olamamaktadır (Broadbent, 1958). Alan yazın incelendiğinde sürdürülebilir dikkatin öğrenme üzerinde etkilerini araştıran çalışmaların var oldukları görülmektedir. Steinmayr, Ziegler ve Träuble (2010), sürdürülebilir dikkat ve zekanın başarıyı yordama durumuna odaklanmışlardır. Çalışmadan elde edilen veriler zekâ ve sürdürülebilir dikkatin ortak etkisinin öğrencilerin yabancı dil notlarını yordamada anlamlı bir sonuç üretmediğini göstermiştir. Schweizer, Zimmermann ve Koch (2000) ise yine sürdürülebilir dikkat ve zekâ arasındaki ilişkiye algısal işlemlerin katkısının araştırıldığı bir çalışma yürütmüşlerdir ve araştırma sonuçları zekânın; sürdürülebilir dikkat, sinyal yakalama hızı ve uyarıcı ayrımı değişkenleri tarafından anlamlı bir şekilde yordandığını ortaya koymuştur. Sürdürülebilir dikkatin gerçek bir sınıf ortamında bireylerin beyinlerinde nasıl bir etki yarattığını belirlemek amacıyla Ko, Komarov, Hairston, Jung ve Lin (2017) tarafından bir EEG temelli bir çalışma yürütülmüş ve bireylere verilen sürdürülebilir dikkat görevinin beyin dalgalarını nasıl etkilediği ortaya koyulmuştur. Ilgaz, Altun ve Așkar (2014) e-öğrenme ortamlarında sürdürülebilir dikkat ve bağlamsal ipucu kullanımının örtük bellek performansına etkilerini inceledikleri çalışmalarında sürdürülebilir dikkatin örtük bellek performansı üzerinde anlamlı bir etkisinin olmadığını bulmuşlardır. Bireylerin farklılıklarına odaklanarak kişiselleştirilmiş öğrenme ortamları sunabilmek için Chen, Wang ve Yu (2017) video derslerde EEG sinyalleri ile öğrencilerin sürdürülebilir dikkat düzeylerini tanıyan bir sistem geliştirmeyi amaçlamışlardır. Öğrencilerin bir video dersi izlerken düşük dikkat düzeylerini tespit edebilen bu sistem sayesinde öğretim tasarımcları dikkat düzeylerinin düştüğü anları belirleyip tasarımları bu durumlara özgü şekillendirmeleri için yardımcı olması beklenmektedir.

Sürdürülebilir dikkati ölçme sürecinde farklı birçok ölçme aracı kullanılmaktadır. Bunlardan bir kısmı kağıt kalem tabanlı (Moosbrugger ve Oehlschlagel, 1996; Wei, Wang ve Klausner, 2012) olurken bazlları da bilgisayar ortamında kullanılan araçlar olarak karşımıza çıkmaktadır. (Buehner, Krumm, Ziegler ve Pluecken, 2006; Egeland ve Kovalik-Gran, 2010; Fisher, Thiessen, Godwin, Kloos ve Dickerson, 2013; Helton ve diğ., 2009; Schweizer ve diğ., 2000). Bilgisayar ortamında kullanılan sürdürülebilir dikkat testi araçlarının bir kısmında çoklu nesne takibi paradigması yer almaktadır. Çoklu nesne takibi paradigması bireylerin görsel sisteminin çoklu hareket eden nesneleri nasıl takip ettiğini çalışan bir deneysel tekniktir. İlk 
olarak 1988 yılında geliştirilmiştir ve görsel indeks adı verilen mekanizmayı test etmek ve görselleștirmek amaçlanmıștır (Pylyshyn ve Storm,1988).

$\mathrm{Bu}$ araştırma kapsamında da çoklu nesne takibi paradigmasına göre Haladjian ve Pylyshyn (2006) tarafından geliştirilmiş olan Çoklu Nesne Takibi Testi kullanılmıştır.

\section{Araştırmanın Amacı}

Bu çalışmanın amacı sürdürülebilir dikkati ölçmek için geliştirilen bir ölçme deney setinin Türkiye grubunda norm analizlerinin yapılmasıdır. Bu amaç bağlamında Ilgaz, Altun ve Aşkar (2014) tarafından Türkçe diline uyarlanan ve dört aşamalı hale getirilen testin uygulaması yapılarak, cinsiyet ve yaş değişkenleri açısından dağılımları rapor edilmiştir.

\section{YÖNTEM}

Araştırma betimsel araştırma yöntemleri kullanılarak yürütülmüştür. Bu bağlamda elde edilen veriler analiz edilerek raporlanmıştır.

\section{Sürdürülebilir Dikkat Testi}

İlgili testin özgün hali üç aşamadan oluşmaktadır. Ancak ilk olarak katılımcılara alıştırma oturumu sunulmuş ve test dört aşamalı olarak olușturulmuștur. Alıștırma oturumundan sonra ana uygulamada ekrana sekiz adet top gelmektedir. Bu toplardan her seviyeye uygun olarak belli bir sayıda top yanıp sönerek katılımcının takip etmesi gereken toplar gösterilmektedir. $\mathrm{Bu}$ aşamadan sonra tüm toplar -içleri dolu bir şekilde- 10 saniye boyunca ekranda rastgele hareket etmektedirler. Katılımcılardan en başta yanıp sönen hedefleri takip etmeleri ve tüm toplar durduğu zaman hedefleri tespit etmeleri beklenmektedir. Testin asıl uygulamasına geçmeden önce alıştırma oturumu yapılmaktadır, bu aşamadan sonra katılımcılara kolay, orta ve zor seviyedeki oturumlar sunulmaktadır. Kolay seviyede toplam sekiz nesneden bir tanesi hedef, orta seviyede toplam sekiz nesneden iki tanesi hedef ve zor seviyede toplam 8 nesneden 4 tanesi hedef olarak yer almaktadır ve her seviye $10 \mathrm{kez}$ tekrar etmektedir. Testin her aşamasından en az 0, en fazla 10 puan alınmaktadır. Testin her bir aşaması üç-dört dakika sürmektedir ve toplam uygulama süresi yaklaşık 15 dakikadır. Testte katılımcıların bulmaları gereken hedef nesneler ile hedefte olmayan nesnelerin ayırt edilebilirliğine ilișkin olarak yapılan ANOVA analizi sonucunda katılımclların tepki sürelerinin hedef nesnelerde, hedef olmayanlara göre daha iyi sonuçlar üretmiş olduğu belirlenmiştir $\left(\mathrm{F}_{(1,24)}=9.617, \mathrm{p}=.005\right)$. Bu da hedef olarak işaretlenen nesnelerin herhangi bir açık görev olmadan bile takip edilebildiğini göstermektedir (Haladjian ve Pylyshyn, 2006). Sürdürülebilir dikkat testine ilişkin örnek ekran gösterimleri, Şekil 1'de yer almaktadır. Soldaki görüntü her bir oturumda topların yanıp söndüğü anı, sağdaki görüntü ise katılımcıların işaretlemesi için topların hareketinin durdurduğu anı göstermektedir.

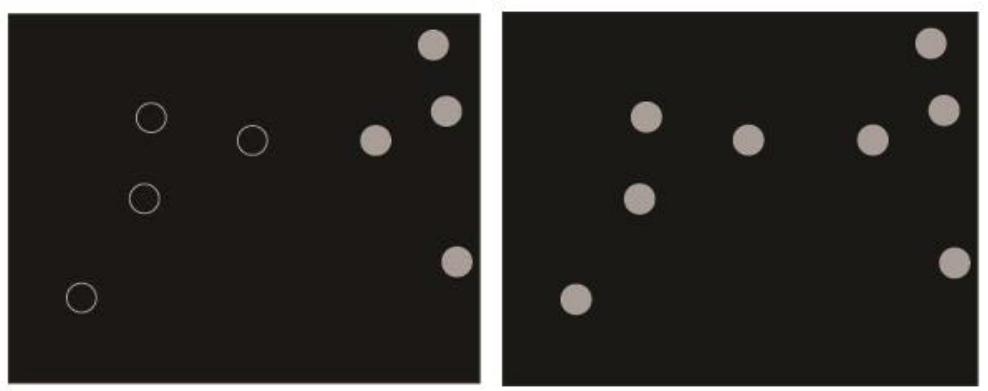

ŞEKİL 1. Sürdürülebilir dikkat testine ilişkin görüntüler

\section{Testin Uygulanması}

MATLAB (R2017b, 64-bit) yazılımı üzerinde Psychtoolbox-3 eklentisi kullanılarak çalıştırılan sürdürebilir dikkat testi, dokunmatik bir LCD monitör üzerinde çalışmaktadır. 
Ekran üzerinde yansıma olmaması için uygulama ortamının mümkün olduğunca karartılmasına özen gösterilmiştir. Birebir uygulamalar, ses ve havalandırma açısından uygun bir odada gerçekleștirilmiştir. Üniversitede bir çalıșma odası, uygulama süreci boyunca deneylerin gerçekleştirilmesi için düzenlenmiştir. Testler, araștırmacılar eşliğinde bireysel olarak gerçekleştirilmiştir. Uygulama öncesinde katılımcılara etik kurul izni, testin uygulanma sürecine ilişkin bir yönerge ve aydınlatılmış onam formu sunularak imzaları alınmıştır. Bunun yanı sıra katılımcılar ile ilgili demografik bilgiler (bölüm, cinsiyet, yaş, sınıf düzeyi, görme bozukluğu durumu) testin uygulanmasından önce doğrudan katılımcılara sorularak kaydedilmiştir. Ardından teste ilişkin katılımcıların soruları yanıtlanmıştır. Katılımcı, testi yalnız yürütebileceğini ve hazır olduğunu belirttikten sonra test başlatılmıștır. Test aşamaları arasında katılımcılara ekran üzerinde ne yapmaları gerektiği yönergeler ile bildirilmiștir. Testin tüm aşamaları tamamlandığında test bitmektedir. Dikkat testi uygulamasına ilișkin örnek bir görüntü, Şekil 2'de gösterilmektedir. Örnek görüntü, ilgili katılımcının bilgisi ve onayı dahilinde paylaşılmaktadır.

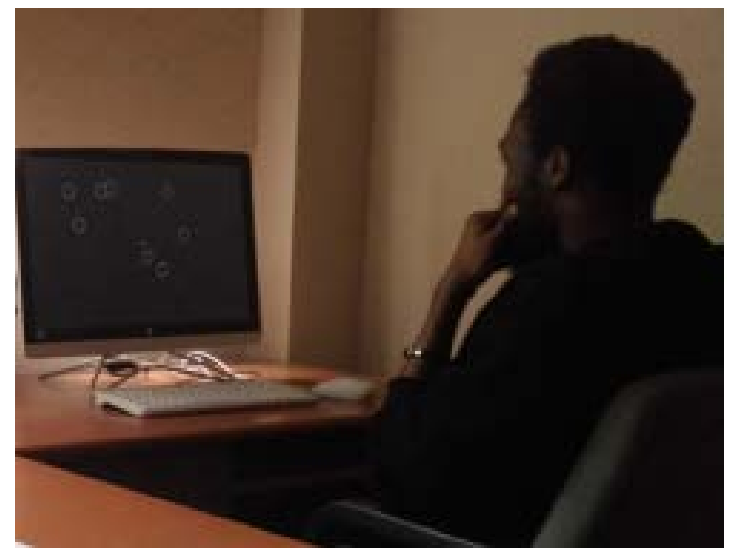

ŞEKIL 2. Test uygulamasına ilişkin bir örnek

\section{Çalışma Grubu}

Araştırmaya, ileri derece görme bozukluğu olmayan (normal ve düzeltilmiş görüş) 88 kadın ve 113 erkek olmak üzere toplam 201 üniversite öğrencisi katılmıştır. Çalışmaya katılan öğrenciler tamamen gönüllük esasına göre çalışmada yer almışlardır. Uygulama sonunda dileyen öğrencilere testten almış oldukları puanlar bildirilmiştir. Çalışmaya katılan öğrencilere ilişkin demografik veriler Tablo 1'de yer almaktadır.

Tablo 1. Katılımcılara ait demografik veriler

\begin{tabular}{llcc}
\hline Değişkenler & & $\mathbf{N}$ & $\mathbf{\%}$ \\
\hline \multirow{2}{*}{ Cinsiyet } & Kadın & 88 & 43.8 \\
& Erkek & 113 & 56.2 \\
\hline \multirow{3}{*}{ Sınıf } & 2 & 62 & 30.8 \\
& 3 & 92 & 45.8 \\
& 4 & 47 & 23.4 \\
\hline \multirow{4}{*}{ Bölümm } & BÖTE & 176 & 87.6 \\
& Fen Bilgisi Ö. & 9 & 4.5 \\
& Okul Öncesi Ö. & 4 & 2.0 \\
& Sinıf Ö. & 4 & 2.0 \\
& Sosyal Bilgiler Ö. & 6 & 3.0 \\
\multirow{3}{*}{ Yaş } & Türkçe Ö. & 2 & 1.0 \\
& 19-21 & 116 & 57.7 \\
& $22-24$ & 69 & 34.3 \\
\hline
\end{tabular}




\section{Verilerin Analizi}

Verilerin analizinde SPSS 17.0 istatistiksel analiz programı kullanılmıştır. Analizlerden önce verilerin dağılımı Kolmogorov-Smirnov (K-S) testi ile analizlere dahil edilen tüm gruplar bazında kontrol edilmiştir. Normallik testi sonucunda yaş ve cinsiyet değişkenlerinde 1 kategorinin normal dağılım göstermediği bulunmuştur. Bu nedenle parametrik olmayan istatistiksel analizlerden Mann Whitney $U$ ve Kruskal Wallis $H$ testleri kullanılmıștır. Analizlerden elde edilen bulguların yorumlanmasında 0.05 anlamlılık düzeyi esas alınmıştır.

\section{BULGULAR}

$\mathrm{Bu}$ bağlamda katılımcıların sürdürülebilir dikkat testinin aşamalarından aldıkları minimum, maksimum test puanları, ortalama değerleri ve standart sapmaları Tablo 2'de yer almaktadır.

Tablo 2. Sürdürülebilir dikkat testi betimsel analizleri

\begin{tabular}{lccccc}
\hline Așamalar & N & Minimum & Maksimum & Ortalama & Standart Sapma \\
\hline Kolay & 201 & 2 & 10 & 9.02 & 1.24 \\
Orta & 201 & 1 & 10 & 7.31 & 2.05 \\
Zor & 201 & 0 & 10 & 4.88 & 2.60 \\
\hline
\end{tabular}

Sürdürülebilir dikkat testinden elde edilen puanlar incelendiğinde testin zorluk derecesi arttıkça ortalama puanların da azaldığı görülmektedir.

Sürdürülebilir dikkat testinin genelinden elde edilen puanlar, aşamalarından elde edilen puanlar ve cinsiyet değiş̧keni arasındaki ilişkiyi belirlemek için Mann Whitney U-testi uygulanmıştır. Yapılan analize ilişkin sonuçlar Tablo 3'de yer almaktadır.

Tablo 3. Sürdürülebilir dikkat testi puanlarının cinsiyete göre U testi sonuçları

\begin{tabular}{llccccc}
\hline Grup & Cinsiyet & $\mathbf{n}$ & $\begin{array}{c}\text { Sıra } \\
\text { Ortalaması }\end{array}$ & $\begin{array}{c}\text { Sıra } \\
\text { Toplamı }\end{array}$ & U & p \\
\hline \multirow{2}{*}{ Kolay } & Kadın & 88 & 88.20 & 7761.50 & 3845.50 & .003 \\
& Erkek & 113 & 110.97 & 12539.50 & & \\
\hline \multirow{2}{*}{ Orta } & Kadın & 88 & 78.29 & 6889.50 & 2973.50 & .000 \\
& Erkek & 113 & 118.69 & 13411.50 & & \\
\hline \multirow{2}{*}{ Zor } & Kadın & 88 & 71.87 & 6324.50 & 2408.50 & .000 \\
& Erkek & 113 & 123.69 & 13976.50 & & \\
\hline \multirow{2}{*}{ Genel Ortalama } & Kadın & 88 & 72.63 & 6391.50 & 2475.50 & .000 \\
& Erkek & 113 & 123.09 & 13909.50 & & \\
\hline
\end{tabular}

Katılımcıların sürdürülebilir dikkat testinden aldıkları puanlar cinsiyet değişkenine göre tüm düzeylerde anlamlı bir farklılık göstermektedir. Sıra ortalamaları incelendiğinde erkek katılımcıların sürdürülebilir dikkat performanslarının testin her üç aşamasında da kadın katılımcılara göre daha yüksek çıktığı görülmektedir.

Sürdürülebilir dikkat testinin genelinden elde edilen puanlar, aşamalarından elde edilen puanlar ve katılımcıların yaş değişkeni arasındaki ilişkiyi belirlemek için Kruskal Wallis $\mathrm{H}$ testi uygulanmıștır. Yapılan analize ilişkin sonuçlar Tablo 4'de yer almaktadır. 
Tablo 4. Sürdürülebilir dikkat testi puanlarının yaş değişkenine göre Kruskal Wallis H sonuçları

\begin{tabular}{|c|c|c|c|c|c|c|}
\hline & & $\mathbf{n}$ & $\begin{array}{c}\text { Sira } \\
\text { Ortalaması }\end{array}$ & sd & $\chi^{2}$ & p \\
\hline \multirow{3}{*}{ Kolay } & $19-21$ & 116 & 103.66 & 2 & 1.647 & .439 \\
\hline & $22-24$ & 69 & 100.22 & & & \\
\hline & 25 ve üstü & 16 & 85.13 & & & \\
\hline \multirow{3}{*}{ Orta } & $19-21$ & 116 & 99.66 & 2 & .852 & .653 \\
\hline & $22-24$ & 69 & 105.34 & & & \\
\hline & 25 ve üstü & 16 & 92.00 & & & \\
\hline \multirow{3}{*}{ Zor } & $19-21$ & 116 & 101.13 & 2 & .377 & .828 \\
\hline & $22-24$ & 69 & 102.67 & & & \\
\hline & 25 ve üstü & 16 & 92.84 & & & \\
\hline \multirow{3}{*}{$\begin{array}{l}\text { Genel } \\
\text { Ortalama }\end{array}$} & $19-21$ & 116 & 101.26 & 2 & .832 & .660 \\
\hline & $22-24$ & 69 & 103.40 & & & \\
\hline & 25 ve üstü & 16 & 88.75 & & & \\
\hline
\end{tabular}

Analizden elde edilen sonuçlara bakıldığında katılımcıların bulundukları yaş değişkeni ve sürdürülebilir dikkat performansları arasında bir ilişki olmadığını göstermektedir.

Bu analizlere ek olarak katılımcıların dikkat düzeylerine göre yüksek ve düșük olarak iki gruba ayrılmıştır. Bu amaçla alt - üst \%27'lik gruplara ayırma tekniği kullanılmıştır. Buna göre 201 katılımcı 3 aşamalı çoklu nesne takibi testinden aldıkları puanların ortalamalarına göre en yüksekten en düşüğe doğru sıralanmıș ve ilk \%27'si "yüksek" grup; son \%27'si "düşük" grup olarak belirlenmiștir. Sürdürülebilir dikkat düzeylerine göre gruplara ayırma süreci sonucunda katılımcılardan 54 kişi düşük, 54 kişi ise yüksek grupta yer almıştır. Ancak düşük gruptaki kişilerle aynı ortalamaya sahip 6 kişi daha ilgili gruplara alınmıştır. Yüksek grupta da aynı şekilde 4 kişi ilk gruplamadaki kişilerle aynı puanı aldığı için yüksek gruba eklenmiştir. Bu işlem sonucunda düşük grupta 60 kişi yüksek grupta ise 58 yer almaktadır.

\section{TARTIŞMA VE SONUÇ}

$\mathrm{Bu}$ çalışma ile bilgisayar ortamında kullanılabilecek sürdürülebilir dikkat testinin norm çalışmasının yapılması amaçlanmıştır. Haladjian ve Pylyshyn (2006) tarafından geliştirilmiş olan çoklu nesne takibi testi bu amaç doğrultusunda Türkçe diline çevrilmiş ve 4 aşamalı bir yapıya getirilmiştir. Öğrenme ve bellek süreçlerinde seçici algı ve dikkat bilginin belli bir kısmının alınmasında, belli bir kısmının alınmamasında etkili olmaktadır. Dolayısıyla e-öğrenme ortamları gibi uyaranın fazla olduğu öğrenme ortamlarında bireylerin dikkat düzeylerinin göz önünde bulundurulması önemlidir.

Yaş, cinsiyet, sosyo-ekonomik statü gibi demografik değişkenler birçok araştırma konusu için olduğu gibi bilișsel süreçleri ele alan çalışmalar için de önemli değişkenlerdendir. $\mathrm{Bu}$ çalıșmadan elde edilen verilere cinsiyet değișkeni açısından bakıldığında test aşamaları ilerledikçe erkek katılımcıların kadın katılımcılara göre testten daha yüksek puanlar aldıklarını göstermektedir. Chan (2001), sürdürülebilir dikkatin cinsiyet değişkeni açısından ele alındığı araştırmasında, cinsiyet değişkeni bağlamında anlamlı bir farklılık bulamamıştır, ancak Riley ve diğ. (2016)'nin araștırmalarında erkeklerin kadınlara göre daha iyi performans gösterdiklerini ortaya koyan bulgular edinilmiștir. Bunun yanı sıra erkek bireylerin dikkat düzeylerinin daha yüksek olduğu (Blatter ve diğ., 2006); kadınlarda ise baskılayıcı unsurların daha fazla gözlemlendiği raporlanmıştır (Yuan, He, Qinglin ve Chen, 2008).

$\mathrm{Bu}$ çalışmada, katılımcıların yaş gruplarına göre sürdürülebilir dikkat performansları arasında anlamlı bir ilişki bulunamamıştır. Dye ve Hauser (2014) sağır ve işiten çocukların sürdürülebilir dikkat düzeylerini inceledikleri çalışmalarında her iki gruptaki çocuklar için yaş grupları arasında anlamlı farklılık bulmuşlardır. Gelişimsel olarak sürdürülebilir dikkat performansı çocukluk dönemlerini kapsayan dönemlerde çalışılan bir konu olarak yer 
almaktadır (Betts, McKay, Maruff ve Anderson, 2006; Lin, Hsiao ve Chen, 1999). Özellikle çocukluk çağında 5-6 ve 11-12 yaşları arasında sürdürülebilir dikkatin gelişimi ve nasıl geliştiğine ilişkin araştırma sonuçları bu süreci modellemektedir (Klenberg, Korkman ve LahtiNuuttila, 2001; Manly ve diğ., 2001; Rebok, ve diğ., 1997). Bu çalışma kapsamında yer alan katılımcıların yetişkin bireylerden oluşması ve yaş gruplarına göre sürdürülebilir dikkat performansının anlamlı farklılı ortaya koymaması, dikkat gelişim sürecinin büyük ölçüde tamamlanmış olmasından kaynaklı görülebilir.

Özellikle bireysel farklılıkları göz önüne alarak tasarlanan uyarlanabilir e-öğrenme ortamları için bilişsel tabanlı farklılıkların belirlenip bunlara özgü tasarımlar yapılması sürecin etkililiği ve verimliliği açısından oldukça önemlidir. İçeriklerin farklı biçimlerde tasarlanması ve bireylerin özelliklerinin bir arada değerlendirilmesi de gerekli olmaktadır.

Bu çalışmadan elde edilen verilerle bilgisayar ortamında sunulan bir sürdürülebilir dikkat testine ilişsin norm değerlerinin ortaya konması amaçlanmıştır. Araştırmaya sadece iki devlet üniversitesinin Eğitim Fakültesi öğrencileri dahil edilmiştir. Farklı bölgelerdeki okullardan ve farklı alanlardan bireylerin yer alması çalışmanın genellenebilirliğini arttıracaktır.

\section{KAYNAKÇA}

Atkinson, R. C., \& Shiffrin, R. M. (1968). Human memory: A proposed system and its control processes. In K. W. Spence, \& J. T. Spence(Eds.), The psychology of learning and motivation. New York: Academic Press.

Betts, J., McKay, J., Maruff, P., \& Anderson, V. (2006). The development of sustained attention in children: the effect of age and task load. Child Neuropsychology, 12(3), 205-221. doi: $10.1080 / 09297040500488522$

Blatter, K., Graw, P., Muench, M., Knoblauch, V., Wirz-Justice, A., \& Cajochen, C. (2006). Gender and age differences in psychomotor vigilance performance under differential sleep pressure conditions. Behavior Brain Research, 168, 312-317. doi: 10.1016/j.bbr.2005.11.018 PMID: 16386807

Broadbent, D. (1958). Perception and communication. London: Pergamon Press.

Buehner, M., Krumm, S., Ziegler, M., \& Pluecken, T. (2006). Cognitive abilities and their interplay: Reasoning, crystallized intelligence, working memory components, and sustained attention. Journal of Individual Differences, 27(2), 57-72. doi: 10.1027/1614-0001.27.2.57

Chan, R. C. K. (2001). A further study on the sustained attention response to task (SART): the effect of age, gender and education. Brain Injury, 15(9), 819-829. doi: 10.1080/02699050110034325

Chen, C.-M., Wang, J.-Y., \& Yu, C.-M. (2017). Assessing the attention levels of students by using a novel attention aware system based on brainwave signals. British Journal of Educational Technology, 48(2), 348-369. doi: 10.1111/bjet.12359

Deutsch, J. A., \& Deutsch, D. (1963). Attention: some theoretical considerations. Psychological Review, 70, 80-90.

Dye, M. W. G., \& Hauser, P. C. (2014). Sustained attention, selective attention and cognitive control in deaf and hearing children. Hearing research, 309, 94-102. doi: 10.1016/j.heares.2013.12.001

Egeland, J., \& Kovalik-Gran, I. (2010). Measuring several aspects of attention in one test: the factor structure of conners's continuous performance test. Journal of Attention Disorders, 13(4), 339-346. doi: $10.1177 / 1087054708323019$

Fisher, A., Thiessen, E., Godwin, K., Kloos, H., \& Dickerson, J. (2013). Assessing selective sustained attention in 3- to 5-year-old children: evidence from a new paradigm. Journal of Experimental Child Psychology, 114(2), 275-294. doi: 10.1016/j.jecp.2012.07.006

Haladjian, H. H., \& Pylyshyn, Z. W. (2006). Implicit multiple object tracking without an explicit tracking task. Journal of Vision, 6(6), 773-773. doi: 10.1167/6.6.773

Helton, W. S., Kern, R. P., \& Walker, D. R. (2009). Conscious thought and the sustained attention to response task. Consciousness and Cognition, 18(3), 600-607. doi: 10.1016/j.concog.2009.06.002 
Ilgaz, H., Altun, A. \& Aşkar, P. (2014). The effect of sustained attention level and contextual cueing on implicit memory performance for e-learning environments. Computers in Human Behavior, 39(0), 1-7. doi: 10.1016/j.chb.2014.06.008

James, W. (1890). Principles of psychology (Vol.1). New York: Holt.

Kahneman, D. (1973). Attention and effort. Englewood Cliffs, NJ: Prentice-Hall.

Klenberg, L., Korkman, M., \& Lahti-Nuuttila, P. (2001). Differential development of attention and executive functions in 3- to 12-year-old Finnish children. Developmental Neuropsychology, 20(1), 407-428.

Ko, L.-W., Komarov, O., Hairston, W. D., Jung, T.-P., \& Lin, C.-T. (2017). Sustained attention in real classroom settings: An EEG study. Frontiers in Human Neuroscience, 11, 388-388. doi: 10.3389/fnhum.2017.00388

Lin, C. C. H., Hsiao, C. K., \& Chen, W. J. (1999). Development of sustained attention assessed using the continuous performance test among children 6-15 years of age. Journal of Abnormal Child Psychology, 27(5), 403-412. doi: 10.1023/a:1021932119311

Manly, T., Anderson, V., Nimmo-Smith, I., Turner, A., Watson, P., \& Robertson, I.H. (2001). The differential assessment of children's attention: The test of everyday attention for children (TEA-Ch), normative sample and ADHD performance. Journal of Child Psychology, 42(8), 1065-1081.

Moosbrugger, H. \& Oehlschlägel, J. (1996). FAIR. Frankfurter Aufmerksamkeitsinventar. Bern: Huber

Pylyshyn, Z.W. \& Storm, R.W. (1988). Tracking multiple independent targets: evidence for a parallel tracking mechanism. Spatial Vision, 3(3), 1-19.

Rebok, G. W., Smith, C. B., Pascualvaca, D. M., Mirsky, A. F., Anthony, B. J., \& Kellam, S. G. (1997). Developmental changes in attentional performance in urban children from eight to thirteen years. Child Neuropsychology, 3(1), 28-46.

Riley, E., Okabe, H., Germine, L., Wilmer, J., Esterman, M., \& DeGutis, J. (2016). Gender Differences in Sustained Attentional Control Relate to Gender Inequality across Countries. PloS one, 11(11), e0165100-e0165100. doi:10.1371/journal.pone.0165100

Roda, C. (2011). Human attention in digital environments. NY: Cambridge University Press.

Sarter, M., Givens, B., \& Bruno, J. P. (2001). The cognitive neuroscience of sustained attention: where topdown meets bottom-up. Brain Research Reviews, 35(2), 146-160.

Schweizer, K. (2010). The relationship of attention and intelligence. In A. Gruszka, G. Matthews, \& B. Szymura (Eds.), Handbook of Individual Differences in Cognition: Attention, Memory, and Executive Control (pp. 247-262). New York, NY: Springer New York.

Schweizer, K., Zimmermann, P., \& Koch, W. (2000). Sustained attention, intelligence, and the crucial role of perceptual processes. Learning and Individual Differences, 12(3), 271-286. doi: 10.1016/s1041$6080(01) 00040-1$

Solso, R., Maclin, K. M., \& Maclin, O. H. (2009). Bilişsel psikoloji (A. Ayçiçeği-Dinn, Trans.). İstanbul: Kitabevi.

Steinmayr, R., Ziegler, M., \& Träuble, B. (2010). Do intelligence and sustained attention interact in predicting academic achievement? Learning and Individual Differences, 20(1), 14-18. doi: 10.1016/j.lindif.2009.10.009

Treisman, A. M. (1964). Selective attention in man. British Medical Bulletin, 20(1), 12-16.

Treisman, A. M. (1960). Contextual cues in selective listening. Quarterly Journal of Experimental Psychology, 12(4), 242-248. doi: 10.1080/17470216008416732.

Wei, F.-Y. F., Wang, Y. K., \& Klausner, M. (2012). Rethinking college students' self-regulation and sustained attention: Does text messaging during class influence cognitive learning? Communication Education, 61(3), 185-204. doi: 10.1080/03634523.2012.672755

Yuan, J., He, Y., Qinglin, Z., Chen, A., \& Li, H. (2008). Gender differences in behavioral inhibitory control: ERP evidence from a two-choice oddball task. Psychophysiology, 45, 986-993. doi: 10.1111/j.14698986.2008.00693.x PMID: 18778319 